\title{
EDITORIAL
}

\section{NEED OF OUR TIMES: IMPACT OF GENOME EDITING SCIENCES AND REQUISITE PREPAREDNESS FOR MOLECULAR BIOTERRORISM}

1. The pace of human evolution has accelerated at an unprecedented rate in the last couple of decades. Never ever before the mankind could witness a global hostage situation by a tiny invisible RNA creature. While the global community struggles at large finding plausible solutions in the information replete era, there are serious lessons to be learnt. The tiny RNA monster has exposed the vulnerabilities of one the considered most intelligent creature posing a question mark about how to strike the intricate balance between preventive approaches and acquiring the postexposure immunity ${ }^{1}$. The rapidly improving genome editing methods along with synthetic genomics has emerged as a double-edged weapon where on one side it opens newer therapeutic avenues to cure disease, but also its malicious use could results in disasters of limitless magnitudes ${ }^{2}$. The delicate boundaries nature may face terrorism in newer clothes at the hands of nano technological tools to modify genome and synthesizing newer life forms ${ }^{3}$. Unstoppable if it becomes can create man-made disasters with issues leading to emergence of black markets for cloning, designer humans ethnic-specific nucleotide editing for worse and possibly much more ${ }^{4,5}$. The fiction we saw yesterday is today's science and can lead the human race to point of no return. "He Jiankui affair" is still one of the genome editing dilemma widely criticized for ethical concerns emerging from germ line editing two human embryos for HIV using Cluster Regularly Interspaced Short Palindromic Repeats (CRISPR) Cas technology 6 .

2. At the time of writing this editorial, we are already seeing evidence of unwarranted genome handling. Several countries have developed specific working groups including "American Society of Human Genetic (ASHG)" work group, British Society for Genetic Medicine, International Genetic Epidemiology Society and few others. ASHG in its 2017 position statement has not reco- mmended germ line gene-editing with caution to exercise oversight and need for ethical justification ${ }^{7}$. Though regulations following the rapid surge of genome editing technologies, techniques like type-2 CRISPR/ $\mathrm{Cas}^{9}$ has already been applied to create multiple knock-in and knockout nucleotide sequence changes in Escherichia Coli and others with much greater efficiencies ${ }^{8}$. Provided concerns raised about the potential health hazards and possible use in bioterrorism Gao et al and Bernard et al have suggested the need of several legal measures while consuming/dealing with "Genetically modified food $(\mathrm{GMF})$ " and "Genetically Modified Organism (GMO)" $" 9,10$.

3. Provided our concerns the counter narrative seems stronger and probably can't be managed. We are already seeing the tremendous potential of CRISPR/Cas genome editing methods in development of organoids, cancer therapy, medicinal use in metabolic disorders and probably much more to justify its use in therapeutics and diagnostics ${ }^{11}$. However, with every human plight the future remains susceptible to its eminent rancorous possibilities. Cloning of human organs, though being debated could actually help reduce burden on human organ providers, but with time the efforts may lead to possible "clone banks" and that could pave way to being a perfected human and designer humans ${ }^{12}$. The possible use of human cloning seems desirable in medicinal context but how much and how many can cause ethical dilemma for the community ${ }^{13}$. Before the debate gets extended and unknowns caught us unaware, its time..... time to learn, understand and evolve to strategize actions which are needed to be taken. Before bio weapons, human cloning, GFOs and GMOs haunt the weak we have to start action for protection'. Newer genome editing methods and synthesis of genome is now possible due to development of novel genetic techniques like Zinc Finger Nuclease (ZFN), Transcription Activator-Like Effector Nuc- 
lease (TALENs) and most recently CRISPR techniques 8 .

4. Following is recommended to address possible non-desirable proliferation of genome editing methodologies and synthetic genomics:

a. A working group must be established under the ownership of a senior molecular pathologist to assess current risk assessment due to non-desirable aspects of the gene editing/ developing methods in various set ups.

b. Core objective of the working group should be to assess following:

i. Regular and continuous assessment of gene editing and related techniques in terms of methodologies use, efficiencies in terms of gene-edited product and futuristic research pathways.

ii. Delineate diagnostic, therapeutic and non-clinical usage of gene editing and synthetic genomic advances.

iii. Assessment of all possible human and animal genome editing on germ lines with background of "molecular bioterro-rism" within our and global community.

iv. Understanding most possible risks rela-ted with genome editing and synthesi-zing new genomes for our population.

v. Develop national level regulatory guidelines for:

a) Using gene therapies for therapeutics in line with international guidelines and expert opinions ${ }^{7}$.

b) Guidelines for agriculture and food industry ${ }^{9,10}$.

c) Oversight on newer and re-emerging infections ${ }^{14}$.

d) Oversight on current research and development programs related with synthetic genomics and genome editing

c. Establishing a core laboratory facility to incorporate analytical facilities to assess various categories of editing sciences as per currently established guidelines ${ }^{15}$.

d. Research and development of all genetic methods used in various biological sciences

e. Preventing efforts of illegal and non-ethical attempts of gene modifications in the shape of natural and man-made bio threats in humans, animals and other biological sciences ${ }^{7-10}$.

f. Ensuring cyber security to protect illegitimate use of private genome data hacks and constant oversight on newer misadventures in genome editing sciences ${ }^{16}$.

g. An initial core team above may possibly include an domain specialists with expertise in molecular pathology, genome editing methods, diagnostic sequencing methods, field epidemiology, non-clinical and clinical microbiology, virology, botanical sciences, industrial-scale development of food sciences, veterinary sciences, entomology, bio-informatics, cyber security and expertise in non-conventional threat assessment ${ }^{17-19}$.

The team may guide future course of action starting from human resource addition, professional developments, areas needing specific oversight, developing regulatory guidelines, mechanism to preempt threats and align our country with next-generational molecular level hazards.

5. The novelty associated with genome manipulation, which has surfaced over the last few decades remains undeniably useful if pursued with the laws of medicinal research and human betterment. Nonethelessthe future may witness newer avenues in life forms as microorganisms, purpose-built human and animal kinds, and plant species. The real trepidation will always be the incalculable and infinite risks attached to these experimentation challenging the ways human beings has ever lived according to the laws of nature. A pushing obligation and need of our times remains to be prepared for curtailing and fine-tuning the use of these colossal genome modifying experiments and biotechnology by 
timely developing regulations and domains to work within.

\section{REFERENCES}

1. Phan T. Genetic diversity and evolution of SARS-CoV2. Infect Genet Evol 2020; 81(1): 104260.

2. Coller BS. Ethics of Human Genome Editing. Annu Rev Med 2019; 70(1): 289-305.

3. Jansen HJ, Breeveld FJ, Stijnis C, Grobusch MP. Biological warfare, bioterrorism, and biocrime. Clin Microbiol Infect 2014; 20(6): 488-496.

4. Liao SM. Designing humans: A human rights approach. Bioethics 2019; 33(1): 98-104.

5. Shinwari ZK, Tanveer F, Khalil AT. Ethical issues regarding crispr mediated genome editing. Curr Issues Mol Biol 2018; 26(1): 103-110.

6. Greely HT. CRISPR'd babies: human germline genome editing in the 'He Jiankui affair'. J Law Biosci 2019; 6(1): 111-183.

7. Ormond KE, Mortlock DP, Scholes DT, Bombat Y, Brody LC, Faucett WA, et al. Human germline genome editing. Am J Hum Genet 2017; 101(2): 167-76.

8. Jiang Y, Chen B, Duan C, Sun B, Yang J, Yang S. Multigene editing in the Escherichia coli genome via the CRISPR-Cas9 system. Appl Environ Microbiol 2016; 82(12): 3693-99.

9. Gao M, Li B, Yuan W, Zhao L, Zhang X. Hypothetical link between infertility and genetically modified food. Recent Pat Food Nutr Agric 2014; 6(1): 16-22.

10. Bernard L, Shaha M. Analysedimensionnelle du concept de biosécurité face aux risquesbiologiques [Dimensional analysis of the concept of biosafety due to bioterrorism]. Rech Soins Infirm 2014; 116(1): 13-27.
11. Driehuis E, Clevers H. CRISPR/Cas 9 genome editing and its applications in organoids. Am J Physiol Gastrointest Liver Physiol 2017; 312(3): G257-G265.

12. May J. Emotional reactions to human reproductive cloning. J Med Ethics 2016; 42(1): 26-30.

13. Häyry M. Ethics and cloning. Br Med Bull 2018; 128(1): 15-21.

14. Yang RF, Cui YJ, Li DF. Zhonghua Yu Fang Yi XueZaZhi. 2012; 46(6): 485-487.

15. Jasanoff S, Hurlbut JB, Saha K. Democratic governance of human germline genome editing. CRISPR J 2019; 2(5): 266-271

16. Jones KH, Daniels H, Squires E, Ford DV. Public views on models for accessing genomic and health data for research: mixed methods study. J Med Internet Res 2019; 21(8): e14384.

17. Nicol D, Eckstein L. Gene editing clinical trials could slip through australian regulatory cracks. J Law Med 2019; 27(2): 274-283.

18. McCammon SL, Mendelsohn M. Innovation and the regulation of products of agricultural biotechnology in the United States of America. Transgenic Res 2019; 28 (Suppl 2): 183-186.

19. Bubela T, Kleiderman E, Master Z, Ogbogu U, Zarzeczny A, Knopper BM et al. Canada's assisted human reproduction act: pragmatic reforms in support of research. Front Med (Lausanne) 2019; 6(1): 157-63.

Corresponding Author: Dr Sikandar Hayat Khan

Pakistan Naval Ship, Hafeez

E-8, Islamabad-Pakistan 